\title{
Papers
}

\section{Glycaemic control with continuous subcutaneous insulin infusion compared with intensive insulin injections in patients with type 1 diabetes: meta-analysis of randomised controlled trials}

John Pickup, Martin Mattock, Sally Kerry

\begin{abstract}
Objective To compare glycaemic control and insulin dosage in people with type 1 diabetes treated by continuous subcutaneous insulin infusion (insulin infusion pump therapy) or optimised insulin injections.

Design Meta-analysis of 12 randomised controlled trials.

Participants 301 people with type 1 diabetes allocated to insulin infusion and 299 allocated to insulin injections for between 2.5 and 24 months. Main outcome measures Glycaemic control measured by mean blood glucose concentration and percentage of glycated haemoglobin. Total daily insulin dose.

Results Mean blood glucose concentration was lower in people receiving continuous subcutaneous insulin infusion compared with those receiving insulin injections (standardised mean difference $0.56,95 \%$ confidence interval 0.35 to 0.77 ), equivalent to a difference of $1.0 \mathrm{mmol} / \mathrm{l}$. The percentage of glycated haemoglobin was also lower in people receiving insulin infusion $(0.44,0.20$ to 0.69$)$, equivalent to a difference of $0.51 \%$. Blood glucose concentrations were less variable during insulin infusion. This improved control during insulin infusion was achieved with an average reduction of $14 \%$ in insulin dose (difference in total daily insulin dose $0.58,0.34$ to 0.83), equivalent to 7.58 units/day.

Conclusions Glycaemic control is better during continuous subcutaneous insulin infusion compared with optimised injection therapy, and less insulin is needed to achieve this level of strict control. The difference in control between the two methods is small but should reduce the risk of microvascular complications.
\end{abstract}

\section{Introduction}

Continuous subcutaneous insulin infusion, often called insulin pump therapy, was introduced in the 1970 s as a way of achieving and maintaining strict control of blood glucose concentrations in people with type 1 (insulin dependent) diabetes. ${ }^{1}$ Short acting insulin is infused subcutaneously from a portable pump at one or more basal rates, with boosts in the dose activated by the patient at mealtimes. Overall control, as measured by mean blood glucose concentrations and percentage of glycated haemoglobin, is considerably improved during treatment with insulin infusion pumps compared with the non-optimised insulin injection therapy that was prevalent in management of diabetes until relatively recently. ${ }^{23}$ However, with the emergence of new treatment strategies such as insulin "pens," which encourage multiple injection regimens, and the publication of the diabetes control and complications trial ${ }^{4}$ the importance and utility of intensive insulin injection regimens in achieving near normoglycaemia and slowing the development of microvascular complications has become increasingly apparent.

Though there have been several randomised controlled trials of insulin pumps compared with optimised insulin injection regimens, many had relatively small numbers of participants. ${ }^{5-8}$ Some of these studies showed better control with pumps, ${ }^{56}$ and others showed broadly similar control. ${ }^{78}$

We reviewed the literature on pump therapy and carried out a meta-analysis of glycaemic control and insulin dosage in randomised controlled trials that compared continuous subcutaneous insulin infusion and optimised insulin injection therapy.

\section{Methods}

Identification and selection of trials

To identify published trials that met the inclusion criteria we searched Medline (1975 to 2000) and Embase (1980-2000) for literature on insulin infusion systems/ insulin infusion and the Cochrane database of randomised controlled trials. We also searched a personal (JP) collection of peer reviewed articles and reviews about infusion systems and lists of papers on pump therapy supplied by two manufacturers of insulin infusion pumps (MiniMed and Disetronic). We reviewed cited literature in retrieved articles and information and references supplied by INPUT, a support group for pump patients.

We selected only those studies that were randomised controlled trials of pump therapy compared

\section{Department of Chemical Pathology, Metabolic Unit, Guy's, King's, and St Thomas's Hospitals School of Medicine, Guy's Hospital, London SE1 9RT \\ John Pickup professor of diabetes and metabolism \\ South West Thames Institute for Renal Research, St Helier Hospital, \\ Carshalton, Surrey SM5 1AA \\ Martin Mattock senior research fellow \\ Department of General Practice and Primary Care, St George's Hospital Medical School, London SW17 0RE \\ Sally Kerry lecturer in medical statistics \\ Correspondence to: J Pickup john.pickup@ \\ kcl.ac.uk \\ BMJ 2002;324:1-6}


with optimised insulin injection therapy. We considered optimised injection therapy as part of the trial design if multiple insulin injections were used, there was adjustment of insulin dosages or timing, or both, according to hospital and home monitored blood glucose concentrations, or the authors described the regimen as "intensive" or "optimised." We did not included trials of alternative infusion and injection systems, such as the "pen infuser" and jet injectors, which are not based on electromechanical pumps or regular subcutaneous needle injection. We also excluded short term studies (two weeks' duration on either therapy), those in people with newly diagnosed type 1 diabetes, those in pregnant women with diabetes, controlled trials that were not randomised, those that used non-optimised ("conventional") insulin injection therapy, and those when it was unclear whether injection therapy was optimised. When several publications reported different aspects of the same study-for example, effect on glycaemic control in one paper and subsequently effects on various microvascular complications in another paper-we chose only one paper to represent the trial data on glycaemic control.

We extracted data from text, tables, and graphs. Data were examined independently by two reviewers (JP and MM). Differences over inclusion of studies and interpretation of data were resolved by consensus reached after discussion.

\section{Outcome measures}

We assessed glycaemic control with each method as mean (SD) blood glucose concentration (to include whole blood, plasma, and serum glucose concentration) and percentage of glycated haemoglobin (to include $\mathrm{HbA}_{1 c}, \mathrm{HbA}_{1}$ and glycated haemoglobin measurements made by different methods). We also noted total daily insulin dose on the two regimens. We recorded the type of pump, the type of insulin, and the insulin injection regimen.

\section{Statistical analysis}

We used a random effects model (StataCorp, College Station, TX, USA) for the meta-analysis. We calculated the weighted mean difference of the standardised blood glucose concentration, percentage of glycated haemoglobin, and insulin dosage on pump and injection therapy (that is, the number of SDs of the value) to compensate for different scales (for example, because of different methods of measuring glycated haemoglobin). We calculated the estimated treatment effects in absolute units by multiplying the combined treatment effects by the average pooled SDs in all studies.

We assessed potential publication bias by a funnel plot and Egger's test. ${ }^{9}$ Sensitivity to the estimate of publication bias was assessed by the trim and fill method. ${ }^{10}$ We assessed heterogeneity between trials by the $\chi^{2}$ test. Sources of heterogeneity were assessed with a random effects regression analysis with age, duration of diabetes and treatment, and year of study as independent variables. We tested the robustness of the analyses in sensitivity analyses by comparing the summary results of random effects meta-analysis with meta-analysis using a fixed effect model and analysis with data in absolute rather than standardised units.

We tested the hypothesis that variability in blood glucose concentration was less during continuous insulin infusion than during injection therapy by calculating the ratio of the minimum variance

Characteristics of trials included in meta-analysis of continuous subcutaneous insulin infusion versus intensive insulin injections

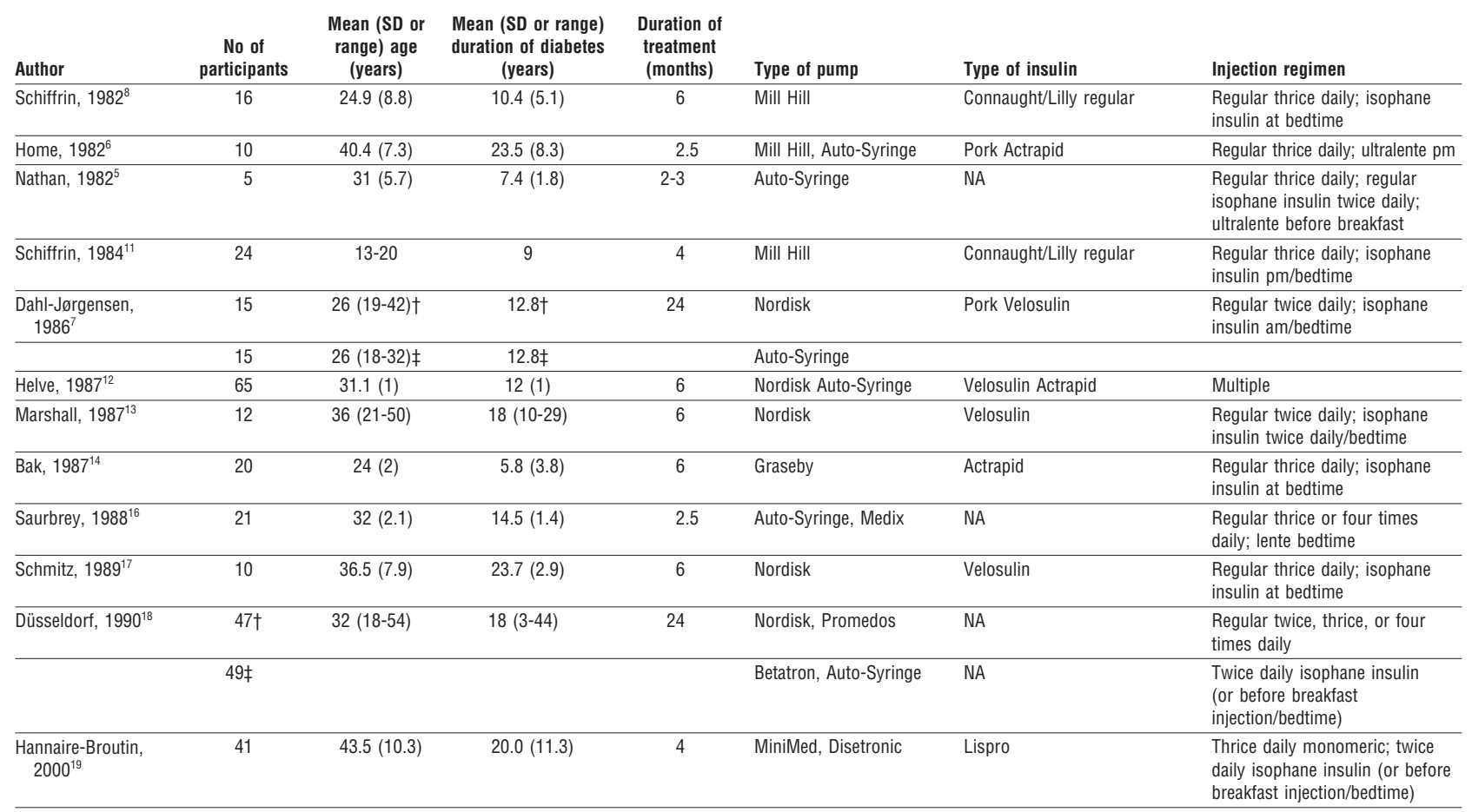

$\mathrm{NA}=$ data not available.

${ }^{*}$ Regular=regular soluble or short acting insulin.

†Participants on injections.

łParticipants on pump therapy. 
weighted geometric means of the SDs of blood glucose concentrations on the two regimens.

\section{Results}

We identified 13 randomised controlled trials that compared glycaemic control on continuous subcutaneous insulin infusion compared with optimised insulin injections..$^{5-8}{ }^{11-19}$ In one report the error terms were ambiguous. As we could not reach consensus about reliable extraction of data we omitted this trial from the analysis. ${ }^{15}$ The table shows the characteristics of the analysed trials. Eleven trials were of crossover

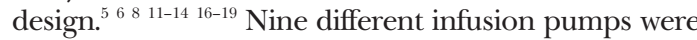
used. In total 301 participants were randomised to infusion pumps and 299 to optimised injections for between 2.5 and 24 months. This represented 2522 patient months of pump treatment.

\section{Blood glucose control}

Figure 1 shows that glycaemic control was better during pump treatment. The standardised mean difference in blood glucose concentrations between insulin pump and optimised insulin injection therapy was $0.56(95 \%$ confidence interval 0.35 to 0.77$)$. The estimate from the fixed effects model was similar $(0.53$, 0.36 to 0.70$)$. The treatment effect in terms of absolute units was $1.06 \mathrm{mmol} / \mathrm{l}(0.88,0.52$ to $1.24 \mathrm{mmol} / \mathrm{l}$ with unstandardised data).

The results of the $\chi^{2}$ tests showed no significant heterogeneity among trials $(\mathrm{P}=0.17)$. There was no clear publication bias in a funnel plot, and the result of Egger's test was not significant $(\mathrm{P}=0.168)$. The trim and fill method gave an estimated corrected effect size of 0.39 (0.15 to 0.63$)$. Only duration of treatment was related to effect size in a regression analysis (regression coefficient $=0.32$ (0.06 to 0.58$)$ ). This model estimated the effect size as $0.46(0.14$ to 0.77$)$ at six months of treatment and 0.93 ( 0.30 to 1.57$)$ at two years.

\section{Glycated haemoglobin}

Figure 2 shows that the percentage of glycated haemoglobin was lower during pump therapy, the standardised mean difference being 0.44 (0.20 to 0.63$)$. This is equivalent to an effect size of $0.51 \%$ in original units, consistent with that seen in a meta-analysis with unstandardised data $(0.45 \%, 0.20 \%$ to $0.71 \%)$. The fixed effect model gave a similar standardised mean difference to the random model $(0.41,0.23$ to 0.58$)$. There was some evidence of heterogeneity $\left(\chi^{2} \mathrm{P}=0.07\right)$, and a funnel plot and Egger's test $(\mathrm{P}=0.02)$ revealed some possible publication bias. The trim and fill method gave an estimated effect size corrected for bias of 0.31 ( 0.15 to 0.48$)$. None of the measured variables was significantly related to effect size in regression analysis.

\section{Insulin dose}

Figure 3 shows that the improved control during insulin pump therapy was achieved at a reduced total daily insulin dosage. The standardised mean difference in insulin dose was 0.58 (0.34 to 0.83). This represents a mean dosage reduction of $14 \%$ during pump therapy. The effect size was 7.58 units/day in original units, which was similar to that seen in a meta-analysis with unstandardised data (7.33, 4.07 to 10.59 units/day).
Schiffrin et al 1982 Home et al $1982^{6}$ Nathan et al $1982^{5}$ Schiffrin et al $1984^{11}$ Dahl-Jørgensen et al $1986^{7}$ Helve et al $1987^{12}$ Marshall et al $1987^{13}$ Bak et al $1987^{14}$ Saurbrey et al $1988^{16}$ Schmitz et al $1989^{17}$ Düsseldorf study $1990^{18}$ Hannaire-Broutin et al $2000^{19}$ Overall $(95 \% \mathrm{Cl})$

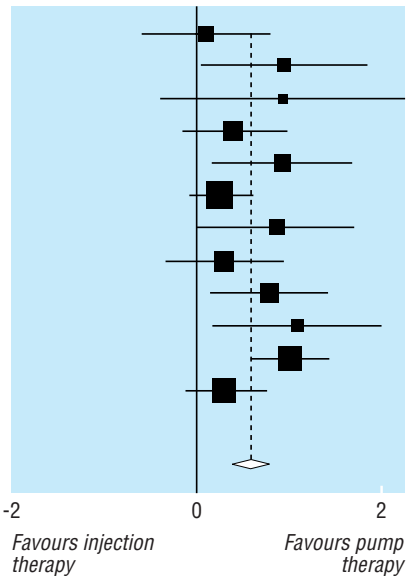

$0.09(-0.61$ to 0.78$)$ $0.92(-0.01$ to 1.85$)$ $0.92(-0.40$ to 2.23$)$ $0.39(-0.18$ to 0.96$)$ 0.92 ( 0.16 to 1.67$)$ $0.25(-0.10$ to 0.59$)$ 0.85 ( 0.01 to 1.69$)$ $0.29(-0.34$ to 0.91$)$ 0.77 (0.14 to 1.40$)$ 1.08 (0.13 to 2.02) $1.00(0.57$ to 1.42$)$ $0.30(-0.13$ to 0.74$)$ $0.56(0.35$ to 0.77$)$

Fig 1 Standardised mean differences (95\% confidence interval) in blood glucose concentration achieved during insulin pump compared with optimised insulin injection therapy

The estimate from the fixed effect model was similar to that of the random effects model $(0.53,0.36$ to 0.71$)$.

Analysis of insulin dose showed some evidence of heterogeneity $(\mathrm{P}=0.07)$. The funnel plot showed some bias, though the result of Egger's test was not significant $(\mathrm{P}=0.17)$. The effect size corrected for bias was 0.42 (0.25 to 0.58$)$. In regression analysis the duration of treatment was negatively related to effect size (regression coefficient $=-0.41(-0.66$ to -0.15$))$. The model estimated the effect size to be 0.66 (0.33 to 0.10$)$ at six months and $0.05(-0.59$ to 0.70$)$ at two years of treatment.

\section{Variability in blood glucose concentration}

Using SD of blood glucose concentration as a measure of glycaemic variability, we found the variability was significantly higher with insulin injections than with pump therapy (weighted geometric mean of the SD ratios $1.27,1.11$ to 1.47 ).

\section{Discussion}

Meta-analysis of 12 randomised controlled trials shows that use of insulin pumps results in better glycaemic

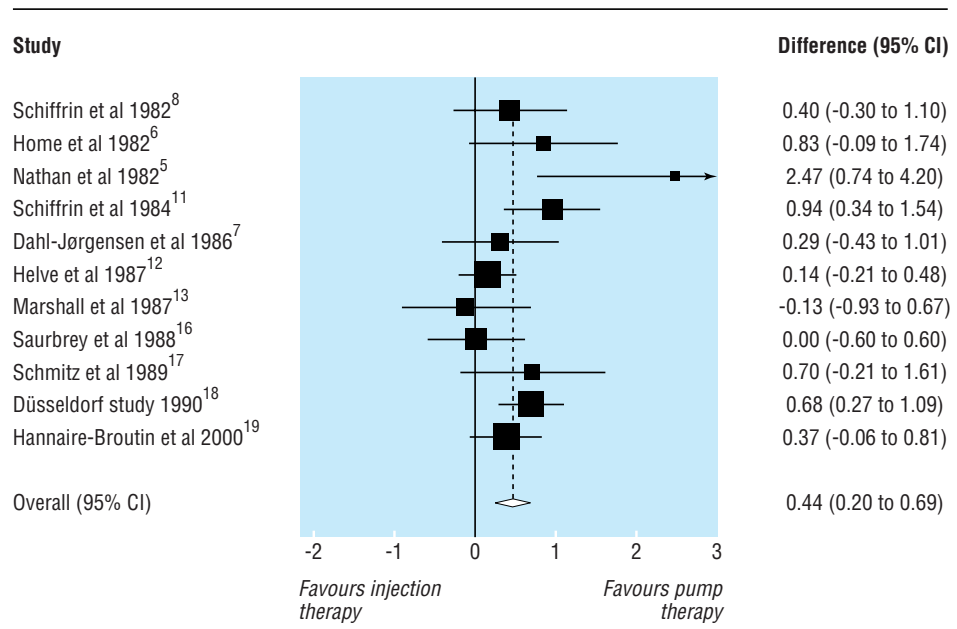

Fig 2 Standardised mean differences (95\% confidence interval) in percentage of glycated haemoglobin during insulin pump compared with optimised insulin injection therapy 


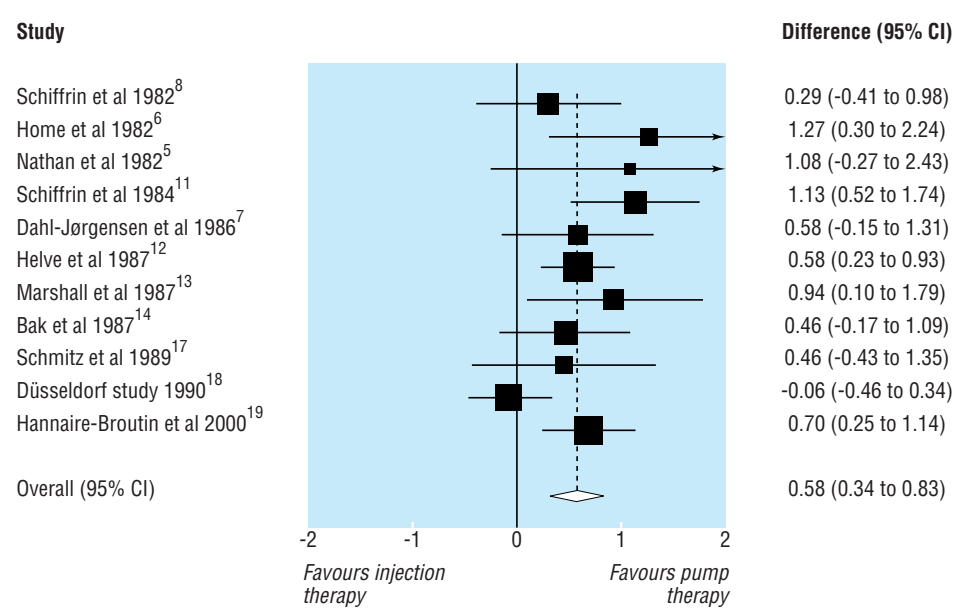

Fig 3 Standardised mean differences (95\% confidence interval) in total daily insulin dose during insulin pump compared with optimised insulin injection therapy control than optimised insulin injection therapy but that the difference is relatively small-about $1 \mathrm{mmol} / \mathrm{l}$ for blood glucose concentration and $0.5 \%$ for percentage of glycated haemoglobin. The main inclusion criterion in the studies was that patients should agree to and be capable of using the pump and its associated procedures. As this is the prerequisite of pump therapy in clinical practice ${ }^{20}$ the results of our meta-analysis are applicable to the general population of people with type 1 diabetes, though few of the participants in these studies had severe complications such as clinical nephropathy (with persistent proteinuria shown by positive result on dipstick testing).

\section{Potential influences on glycaemic control}

Our results of meta-analysis were not modified by the publication date of the trials, though there are several potential reasons why insulin pump therapy in the early 1980s might have been less effective than modern practice. Early pumps had few or no alarm features for events such as low battery or occlusion of delivery and no facility for automatic change in basal rate of infusion. The type of insulin used in the pump might also be important as unbuffered short acting insulin, used particularly in North America in the first years after the introduction of insulin pumps, was more likely than buffered insulins to occlude the delivery cannula and disrupt control. ${ }^{21}{ }^{22}$ The most recent trial in this survey used the monomeric insulin analogue, lispro, in the pump. ${ }^{19}$ This is now considered to be the pump insulin of choice, ${ }^{23-26}$ but the results of the one lispro pump study in this meta-analysis were broadly consistent with the overall result of our analysis (standardised mean differences with lispro were $0.30(-0.13$ to 0.74 ) for blood glucose concentration and 0.37 ( -0.06 to 0.81$)$ for glycated haemoglobin, favouring pump treatment $\left.{ }^{19}\right)$.

Glycaemic control during optimised injection therapy may be affected by the regimen used and the intensity of its application. There were many different injection regimens used in the trials reported here, and we cannot make judgments about their appropriateness. Though this introduces some uncertainty into the conclusions, the results were surprisingly consistent across trials. The only identified source of heterogen- eity was a tendency for trials with a longer duration to be associated with a larger difference in control of glycaemia between pump and injection therapy and a smaller difference in insulin dosage. This finding is consistent with the known effect of pump therapy in improving insulin sensitivity and reducing insulin resistance in people with type 1 diabetes. ${ }^{27} 28$

We excluded from our analysis the few trials in patients with newly diagnosed type 1 diabetes ${ }^{29}$ because the likely remaining endogenous $\beta$ cell function would favour good control in any type of insulin therapy $y^{30}$ and obscure differences between pump and injection treatment. We also did not analyse trials in pregnant women because the number of studies is small ${ }^{31-33}$ and because we considered them to be a special group of patients, with changing control throughout pregnancy and a high level of motivation generally unrepresentative of most people with type 1 diabetes.

\section{Clinical significance of improved control}

What is the clinical significance of the small difference between the strict glycaemic control of pump and optimised injection therapy? Analysis of the results of the diabetes control and complications trial ${ }^{34}$ has shown that the risk of development and progression of microvascular complications extends over the entire range of glycated haemoglobin values and there is no threshold (short of normoglycaemia) below which there is no risk. The standardised mean difference for glycated haemoglobin of 0.44 in this meta-analysis corresponds to a reduction in $\mathrm{HbA}_{1 \mathrm{c}}$ of about $0.5 \%$ in the diabetes control and complications trial (where the SD for $\mathrm{HbA}_{1 \mathrm{c}}$ in the intensively managed group was 1.1-1.3\%). This degree of improvement in control was associated with a reduction in risk of retinopathy of about $25 \%$. However, the relation between the absolute risk (hazard rate per 100 patient years of treatment) and $\mathrm{HbA}_{1 c}$ was curvilinear, with a smaller rate at a lower than at a higher $\mathrm{HbA}_{1 c^{\circ}}$. In people with intensively controlled glycaemia the absolute risk reduction for sustained progression in retinopathy (three steps on the early treatment of diabetic retinopathy scale) associated with a difference in $\mathrm{HbA}_{1 c}$ of $0.5 \%$ was about 0.5 cases per 100 patient years. Thus, maintaining this difference in control between insulin pump and injection therapy for 10 years would reduce the number of patients developing retinopathy of this degree by about 5\%. The cost effectiveness of insulin pump versus insulin injections for this degree of benefit will need to be assessed.

Hypoglycaemia and variability of glycaemic control A weakness of our study is that because of poor reporting and short duration of studies we could not assess the relative frequencies of potential side effects, particularly severe hypoglycaemia, ketoacidosis, and weight gain. For hypoglycaemia, for example, many studies were too short in duration to have more than one episode of severe hypoglycaemic reported on either treatment. ${ }^{5} 681116{ }^{17}$ However, as well as the lower mean blood glucose concentration, we found that oscillations in blood glucose concentration, as measured by SD, were also significantly less during pump treatment. This may contribute to the lower frequency of hypoglycaemia reported in other studies ${ }^{35-38}$ and is probably related to the lower variability in 


\section{What is already known on this topic}

Continuous subcutaneous insulin infusion (insulin pump therapy) produces good long term control of blood glucose concentrations in people with type 1 diabetes

Control of blood glucose concentration is substantially better on pump therapy than conventional (non-optimised) injection therapy

It is unclear how glycaemic control on pump therapy compares with modern optimised insulin injection regimens

\section{What this study adds}

Though glycaemic control was better during continuous subcutaneous insulin infusion than optimised insulin injection therapy, the difference was relatively small

Continuous subcutaneous insulin infusion is an effective form of intensive insulin therapy that should lower the risk of microvascular complications

Insulin pump therapy is unnecessary for most people with type 1 diabetes and should be reserved for those with special problems with optimised insulin injections

subcutaneous insulin absorption during pump infusion compared with injection treatment. ${ }^{39}$

\section{Conclusions and recommendations}

We conclude that continuous subcutaneous insulin infusion is an effective form of intensive insulin therapy for people with type 1 diabetes as glycaemic control is slightly but significantly better than during optimised insulin injections. However we consider that in general insulin pump should be reserved for those with special problems such as unpredictable hypoglycaemia or a marked increase in blood glucose concentration at dawn, despite best attempts to improve control with optimised injection regimens. ${ }^{20} 40$

Contributors: JP initiated the study, analysed the data, wrote the first draft of the paper, and is guarantor. MM analysed the data SK performed the statistical analyses. All authors collaborated on the final version of the paper.

Funding: None.

Competing interests: King's College London has received financial support for some studies on continuous subcutaneous insulin infusion from MiniMed, a manufacturer of insulin pumps.

1 Pickup JC, Keen H, Parsons JA, Alberti KGMM. Continuous subcutaneous insulin infusion: an approach to achieving normoglycaemia. BMJ 1978;i:204-7.

2 Lauritzen T, Frost-Larsen K, Larsen HW, Deckert T. Effect of 1 year of near-normal blood glucose levels on retinopathy in insulin-dependen diabetics. Lancet 1983;i:200-4.

3 Kroc Collaborative Study Group. Blood glucose control and the evolution of diabetic retinopathy and albuminuria. A preliminary multicenter trial. N Engl J Med 1984;311:365-72.

4 Diabetes Control and Complications Trial Research Group. The effect of intensive treatment of diabetes on the development and progression of long-term complications in insulin-dependent diabetes mellitus. $N$ Engl J Med 1993;329:977-86.

5 Nathan DM, Lou P, Avruch J. Intensive conventional and insulin pump therapy in adult type 1 diabetes. A crossover study. Ann Intern Med 1982:97:31-6.
6 Home PD, Capaldo B, Burrin JM, Worth R, Alberti KGMM. A crossover comparison of continuous subcutaneous insulin infusion (CSII) against multiple insulin injections in insulin-dependent diabetic subjects: improved control with CSII. Diabetes Care 1982;5:466-71.

7 Dahl-Jørgensen K, Brinchman-Hansen O, Hanssen KF, Ganes T, Kierulf $\mathrm{P}$, Smeland E, et al. Effect of near-normoglycaemia for two years on progression of early diabetic retinopathy, nephropathy, and neuropathy: the Oslo study. BMJ 1986;293:1195-9

8 Schiffrin A, Belmonte MM. Comparison between continuous subcutaneous insulin infusion and multiple injections of insulin. A one-year prospective study. Diabetes 1982;31:255-64

9 Egger M, Smith GD, Schneider M, Minder C. Bias in meta-analysis detected by a simple graphical test. BMJ 1997;315:629-34.

10 Sutton AJ, Abrams KR, Jones DR, Sheldon T, Song F. Methods for meta-analysis in medical research. Chichester: Wiley, 2000.

11 Schiffrin AD, Desrosiers M, Aleyassine H, Belmonte MM. Intensified insulin therapy in the type 1 diabetic adolescent: a controlled trial. Diabetes Care 1984;7:107-13.

12 Helve E, Koivisto VA, Lehtonen A, Pelkonen R, Huttunen JK, Nikkilä EA A crossover comparison of continuous insulin infusion and conventional injection treatment of type 1 diabetes. Acta Med Scand 1987;221:385-93.

13 Marshall SM, Home PD, Taylor R, Alberti KGMM. Continuous subcutaneous insulin infusion versus injection therapy: a randomized cross-ove trial under usual diabetic clinic conditions. Diabetic Med 1987;4:521-5.

14 Bak JF, Nielsen OH, Pedersen O, Beck-Nielsen H. Multiple insulin injections using a pen injector versus insulin pump treatment in young diabetic patients. Diabetes Res 1987;6:155-8.

15 Nosadini R, Velussi M, Fioretto P, Doria A, Avogaro A, Trevisan R, et al. Frequency of hypoglycaemic and hyperglycaemic-ketotic episodes during conventional and subcutaneous continuous insulin infusion therapy in IDDM. Diabetes Nutr Metab 1988;1:289-96.

16 Saurbrey N, Arnold-Larsen S, Møller-Jensen B, Kühl C. Comparison of continuous subcutaneous insulin infusion with multiple insulin injections using the NovoPen. Diabetic Med 1988;5:150-3.

17 Schmitz A, Sandahl-Christiansen J, Kjeldahl-Christiansen C, Hermansen $\mathrm{K}$, Mogensen CE. Effect of pump versus pen treatment on glycaemic control and kidney function in long-term uncomplicated insulin-dependent diabetes mellitus (IDDM). Danish Med Bull 1989;36:176-8.

18 Düsseldorf Study Group. Comparison of continuous subcutaneous insulin infusion and intensified conventional therapy in the treatment of type 1 diabetes: a two-year randomised study. Diabetes Nutr Metab 1990;3:203-13.

19 Hannaire-Broutin H, Melki V, Bessieres-Lacombe S, Tauber J. Comparison of continuous subcutaneous insulin infusion and multiple daily injection regimens using insulin lispro in type 1 diabetic patients on intensified treatment: a randomized study. Diabetes Care 2000;23:1232-5.

20 Pickup JC, Keen H. Continuous subcutaneous insulin infusion in type 1 diabetes. BMJ 2001;322:1262-3.

21 Mecklenburg RS, Guinn TS. Complications of insulin pump therapy: the effect of insulin preparation. Diabetes Care 1985;8:367-70.

22 Eichner HL, Selam J-L, Woertz LL, Cornblath M, Charles MA. Improved metabolic control of diabetes with reduction of occlusions during continuous subcutaneous insulin infusion. Diabetes Nutr Metab 1988; 1:283-7.

23 Melki V, Renard E, Lassman-Vague V, Boivin S, Guerci B, HanaireBroutin $\mathrm{H}$, et al. Improvement of HbA1c and blood glucose stability in IDDM patients treated with lispro insulin analogue in external pumps. Diabetes Care 1998;21:977-81.

24 Renner R, Pfützner A, Trautman M, Harzer O, Sauter K, Landgraf R. Use of insulin lispro in continuous subcutaneous insulin infusion treatment. Diabetes Care 1999;22:784-8.

25 Zinman B, Tildesley H, Chiasson J-L, Tsui E, Strack T. Insulin lispro in CSII: results of a double-blind crossover study. Diabetes 1997;46:440-3.

26 Schmauss S, König A, Landgraf R. Human insulin analogue [LYS(B28),PRO(B29)]: the ideal pump insulin? Diabetic Med 1998; $15: 247-9$

27 Beck-Nielsen H, Richelsen B, Hasling C, Nielsen OH, Hedding L, Sørensen NS. Improved in vivo insulin effect during continuous subcutaneous insulin infusion in patients with IDDM. Diabetes 1984:33:832-37.

28 Simonson DC, Tamborlane WV, Sherwin RS, Smith JD, DeFronzo RA fo the Kroc Collaborative Study Group. Improved insulin sensitivity in patients with type 1 diabetes mellitus after CSII. Diabetes 1985;34(supp 3):80-6

29 De Beaufort CE, Houtzagers CMGJ, Bruining GJ, Aarsen RSR, den Boer NC, Grose WFA, et al. Continuous subcutaneous insulin infusion (CSII) versus conventional injection therapy in newly diagnosed diabetic children: two-year follow-up of a randomized, prospective trial. Diabetic Med 1989;6:766-71.

30 Gonen B, Goldman J, Baldwin D, Goldberg RB, Ryan WG, Blix PM, et al. Metabolic control in diabetic patients. Effects of insulin-secretory reserve (measured by plasma C-peptide levels) and circulating insulin antibodies. Diabetes 1979;28:749-53.

31 Coustan DR, Reece EA, Sherwin RS, Rudolf MCJ, Bates JE, Sockin SM, et al. A randomized clinical trial of the insulin pump vs intensive conventional therapy in diabetic pregnancies. JAMA 1986;255:631-6.

32 Carta Q, Meriggi E, Trossarelli GF, Catella G, Dal Molin V, Menato G, et al. Continuous subcutaneous insulin infusion versus intensive conventional insulin therapy in type I and type II diabetic pregnancy. Diabete Metabolisme 1986;12:121-9.

33 Nosari I, Maglio ML, Lepore G, Cortinovis F, Pagani G. Is continuou subcutaneous insulin infusion more effective than intensive conventional insulin therapy in the treatment of pregnant diabetic women? Diabetes Nutr Metab 1993;6:33-7.

34 Diabetes Control and Complications Trial Research Group. The absence of a glycemic threshold for the development of long-term complications: 
the perspective of the diabetes control and complications trial. Diabetes 1996;45:1289-98.

35 Ng Tang Fui S, Pickup JC, Bending JJ, Collins ACG, Keen H, Dalton N. Hypoglycemia and counterregulation in insulin-dependent diabetic patients: a comparison of continuous subcutaneous insulin infusion and conventional insulin therapy. Diabetes Care 1986;9:221-7.

36 Bending JJ, Pickup JC, Keen H. Frequency of diabetic ketoacidosis and hypoglycemic coma during treatment with continuous subcutaneous insulin infusion. Am J Med 1985;79:685-91.

37 Bode BW, Steed RD, Davidson PC. Reduction in severe hypoglycemia with long-term continuous subcutaneous insulin infusion in type 1 diabetes. Diabetes Care 1996;19:324-7.
38 Boland EA, Grey M, Oesterle A, Fredrickson L, Tamborlane WV. Continuous subcutaneous insulin infusion. A new way to lower risk of severe hypoglycemia, improve metabolic control and enhance coping in adolescents with type 1 diabetes. Diabetes Care 1999;22:1799-84.

39 Lauritzen T, Pramming S, Deckert T, Binder C. Pharmacokinetics of continuous subcutaneous insulin infusion. Diabetologia 1983;24:326-9.

40 Pickup JC. Is insulin pump treatment justifiable? In: Gill GV, Pickup JC, Williams G, eds. Difficult diabetes. Oxford: Blackwell Science, 2001:205-23.

(Accepted 5 November 2001) 